\title{
CIUDADES ESTRATÉGICAS: ENTRE EL EXTRACTIVISMO Y EL NARCOTRÁFICO. LA VIOLENCIA EN EL PARADIGMÁTICO CASO DE LA CIUDAD DE ROSARIO
}

\section{STRATEGIC CITIES: BETWEEN THE EXTRACTIVE AND DRUG TRAFFICKING. VIOLENCE IN THE PARADIGMATIC CASE OF THE CITY OF ROSARIO}

\section{Martin Scarpacci ${ }^{1}$}

\section{Resumen}

En el transcurso de unos pocos años la ciudad de Rosario (Argentina) se convirtió en un caso paradigmático de violencia urbana en la región del Cono Sur. En consecuencia, se analizan las causas y se explora el devenir histórico-político de la ciudad, el país y la región, acción emprendida de manera relacional (ciudad-región y región-resto del mundo). En este sentido, se revela que las transformaciones geográficas del territorio demuestran de manera tangible que los cambios producidos a nivel social tienen una relación directa con los cambios en la matriz productiva de las diferentes escalas territoriales analizadas. Asimismo, se da cuenta de que los altos índices de homicidios de los últimos años son consecuencia del devenir errante en materia de políticas orientadas hacia la población, y cómo por el contrario, las últimas cuatro décadas han logrado de manera óptima los objetivos de proyectar y construir un territorio de extracción para que luego las materias primas sean consumidas por el sistema capitalista mundial, siendo este último el único fin de las grandes alteraciones sufridas en la región sin importar las consecuencias. De esta manera, se intenta demostrar la vinculación existente entre los mercados legales e ilegales de la economía y cómo ésta afecta a la ciudad modificando el espacio donde interactúan las personas con los medios de producción.

Palabras clave: Extractivismo; narcotráfico; territorio; puerto; planificación estratégica.

\begin{abstract}
In the course of a few years, the city of Rosario (Argentina) became a paradigmatic case of urban violence in the Cono Sur. Accordingly, we analyzed the causes and explore the historical-political becoming of the city, the country and the region, from a relational perspective (city-region and region-rest of the world). In this sense, it is revealed that geographical transformations of the territory tangibly demonstrate that changes at the social level are directly related to changes in the productive matrix of all territorial levels analyzed. It also realizes that the high homicide rates in recent years are the result of errant policies oriented to the population, and how on the other hand, the last four decades have achieved optimally the objectives of designing and building a territory of extraction in order to raw materials are consumed by the world capitalist system, the latter being the only end of major alterations undergone in the region regardless of the consequences. In this way, we try to demonstrate the link between legal and illegal markets of the economy and how it affects the city, changing the space where people interact with the means of production.
\end{abstract}

Keywords: Extractivism, drug trafficking, territory, port, strategic plannig

\footnotetext{
1 Máster en Estudios Urbanos por la FLACSO sede Ecuador. Coordinador Académico de la Red Latinoamericana de Análisis de Seguridad y Delincuencia Organizada. Investigador de la FLACSO y asistente editorial de la revista URVIO. E-mail: martinescar@hotmail.com
} 
La paradoja en la que se encuentra la región Latinoamericana desde hace casi das décadas, radica en que se goza de una bonanza económica proveniente, por un lado del mercado legal que adoptan o aceptan adoptar, los gobiernos y sectores privados afines a partir de políticas extractivistas y neocoloniales, consecuencia de la reprimarización de la economía latinoamericana. Por otro lado está la acaudalada suma que aporta el dinero proveniente del negocio ilegal del narcotráfico, que se estima que constituye un 10\% del PIB a nivel mundial. En este sentido es necesario tener en cuenta que la región posee una situación de centralidad en el mercado de las drogas, por lo que posiblemente en la región el porcentaje de dinero proveniente del narcotráfico y negocios afines sea mayor.

Se propone reflexionar acerca de qué manera el excedente capitalista de ambos negocios (legales/ilegales) se cristaliza en gran medida en la construcción edilicia o en grandes desarrollos inmobiliarios, pero también a nivel de usos de suelos expandiendo innecesariamente la frontera urbana, subordinando al territorio y la ciudad a las lógicas especulativas de mercado. La decisión de apostar en bienes raíces por parte de los inversores posee al menos tres razones claves; la primera "disimular" el dinero mal habido proveniente del narcotráfico junto con las otras economías del circuito formal, la construcción con su complejidad en cantidades y rubros facilita este accionar; la segunda es la posibilidad de recibir un exuberante plus valor a través de la construcción edilicia en zonas de privilegio consensuadas por el gobierno local con el establishment, sobre todo cuando las políticas urbanas locales o nacionales apuestan a alentar la economía través de este medio que desde los noventas se hace Ilamar Planificación Estratégica; y tercero, por estas regiones del mundo, dadas las experiencias vividas, no se confía en el sistema bancario por lo que se prefiere "ahorrar en ladrillos", en occidente nada más sagrado que la propiedad privada.

Las consecuencias de estos mecanismos de mercantilización y apropiación de la ciudad y el territorio son catastróficas para el sistema urbano-rural, puesto que de esta manera se determinan sectores "ganadores" donde se invierten recursos públicos y privados y en contraposición, pero de manera relacional, surgen los sectores perdedores donde se instaura el olvido y la marginalidad (simplemente para la sociedad gobierno-inversores no es rentable invertir en este sector). El escenario urbano, para estos últimos, se viene pauperizando desde los años setentas con las dictaduras militares llegando hasta los noventas con un desguace estructural del sistema ferroportuario (Rigotti y Martínez de San Vicente, 1991; Schvarzer, 1996).

\footnotetext{
${ }^{2}$ Ahorrar en ladrillos es una expresión popular en la que el ahorrista logra escapar de la liquidez financiera mediante la construcción de inmuebles.
} 
Las familias que integraban este gran sistema industrial de producción vieron desvanecerse frente a sus narices sus ingresos y sus derechos. A la par comenzaba a caer en el olvido la histórica identidad de la ciudad puerto, en este contexto, es natural deducir que sus barrios pasaron, en la lógica neoliberal de los noventa y con la implementación de la Planificación Estratégica, a ser sectores abandonados a su suerte. Así nacen, poco a poco, las nuevas áreas perdedoras de la ciudad. En 1973, cuando recién surgía esta nueva y devastadora era, el geógrafo y antropólogo David Harvey planteaba lo siguiente sobre las ciudades:

Para prever el futuro de un sistema urbano es necesario un conocimiento completo de los procesos que generan cambios y una evolución realista de la dirección hacia la cual está siendo conducido por dichos procesos el sistema social en su conjunto. He centrado mi atención en los mecanismos que rigen la redistribución del ingreso y he sugerido que éstos parecen conducirnos hacia un Estado de mayor desigualdad y mayor injusticia. A menos que esta tendencia actual sea contrarrestada, estoy casi seguro de que habremos de enfrentarnos con un período de intensos conflictos (que pueden ser violentos) dentro del sistema urbano. [...]. Por consiguiente, he llegado a la conclusión de que sería desastroso para el futuro del sistema social seguir adelante con una planificación que facilita las tendencias actuales (Harvey, 2007: 95).

Como auguraba Harvey para las ciudades anglosajonas, el modelo empezaba a imponerse y expandirse, no casualmente en el mismo año de 1973 con el golpe a Salvador Allende se imponía una idea imperialista y neoliberal para Chile primero y para América Latina después. Cabe afirmar que no sólo no se revirtieron los modos de distribución del ingreso, sino que por el contrario, cada vez se concentraron más recursos.

El resultado de estas políticas, que primero fueron de gobiernos dictatoriales y después continuadas por las democracias, es que hoy nos encontrarnos con una geografía urbana profundamente desigual y con un sistema urbano altamente violento, para ser más precisos, en la región más desigual y más violenta del mundo. Estas dos características de la región latinoamericana, mayor desigualdad y violencia, yuxtapuestas a una tercera (altos índices de urbanización) nos describen un escenario sumamente complicado. Vale decir que esta última no es una característica necesariamente negativa. Aunque la yuxtaposición de región más desigual y más violenta sobre el escenario -más urbanizado- del mundo nos presenta un desafío singular. Sin embargo en este último punto, tal vez, se encuentre parte de la solución.

En este complejo contexto no resulta difícil intuir porqué la ciudad de Rosario en particular y las ciudades latinoamericanas en general, poseen los índices de homicidios más altos del mundo. 
Las ciudades vienen sufriendo de manera sistemática una violencia estructural donde, al menor porcentaje de población, es decir a los más favorecidos, los protege el sistema subordinándoles el territorio estratégico urbano-rural para transformarlo en su mercancía de especulación -torres de lujo en el centro, barrios cerrados en la periferia-(Barenboim, 2013); mientras que para la gran mayoría de la población, los más desfavorecidos, el territorio se transforma en el lugar de la exclusión y falta de oportunidades.

En consecuencia la brecha física y social, construida y planificada, separa cada vez más a los diferentes sectores de la ciudad consolidando así estas desigualdades. Cabe resaltar, que si en estos sectores marginales no es rentable invertir en los negocios legales que edifican la fachada turística de la ciudad, pues sí es posible invertir en los negocios ilegales de alta rentabilidad que surgen detrás, en la contracara, en los intersticios negados de la ciudad. En este punto es donde se articulan la marginalidad urbana a los grandes flujos de mercancías legales que circulan por los puertos de la región Rosario con destinos de ultramar, quedando claro que esta parte de la ciudad será la que provea la mano de obra que manipulará la mercancía ilegal como también proveerá gran cantidad de los muertos de este conflícto. En este lado del territorio, agónico y marginal, el negocio del crimen organizado del narcotráfico es el que genera el movimiento económico que la Planificación Estratégica niega, y por lo tanto, en este contexto, adquiere relevancia y poder transformándose en un posibilitador social del "ser" y "pertenecer".

De esta manera, la urbe sucumbe ante dos lógicas relacionales entre sí: la primera, la violencia racional capitalista, particularmente y en gran medida, mediante el dinero proveniente del extractivismo el cual ha generado el cambio de escala y traslado de su puerto, con una significativa reconversión del territorio (negocios legales); la segunda, la violencia del crimen organizado del narcotráfico que arrastra consigo otras violencias (negocios ilegales). Por último, los excedentes económicos de ambos circuitos van a articularse y cubrirse (blanquear dinero ilegal), como ya hemos dicho, en la especulación inmobiliaria más descarnada, consolidando así el círculo virtuoso del desarrollo geografico desigual de la ciudad, la nación y la región.

En esta intruducción, el artículo expone la vinculación existente entre los mercados legales e ilegales de la economía y como ésta afecta a la ciudad modificando su geografía y sus relaciones. Para esto, se tienen en cuenta, como ya hemos dicho, tres características claves de la región Latinoamericana: región más desigual, más violenta y más urbanizada del mundo.

La hipótesis que se sugiere es que el sistema económico legal-ilegal ingiere a la ciudad y al territorio como alimento clave del fin de uno de los ciclos del mercado y, cómo esto afecta a las 
grandes mayorías de población urbana promoviendo, acrecentando y consolidando la desigualdad, la marginación y la violencia.

\section{LA CIUDAD Y LOS CICLOS DEL CAPITAL: UNA APROXIMACIÓN HISTÓRICA AL CRIMEN ORGANIZADO}

El nuevo y resplandeciente espacio público que se presenta como el nuevo "balcón urbano" de la ciudad se construyó a partir del traslado del puerto hacia las vecinas localidades al norte y sur de la ciudad de Rosario, Argentina. De alguna manera repite cien años después lo que había sucedido en el oligárquico Boulevard Oroño a comienzos del siglo XX, donde mediante los ornatos de los palacetes, ajardinamientos y políticas de salubridad se generaba un espacio público para la élite de aquel momento. A comienzo del siglo XXI la historia se repite, pero esta vez en la costa de la ciudad.

Esta situación no es casual, ya que el país atravesaba en su centenario el momento más próspero que nunca antes había conocido, situación por la que Argentina pasaría a ser calificada como "el granero del mundo", mientras que Rosario sería apodada "la Chicago Argentina". En otras palabras, se redunda en una situación semejante a lo acontecido al comienzo de este nuevo milenio con la bonanza económica sojera, y lo sucedido cien años antes con la inserción de la Argentina en el sistema capitalista mundial como proveedora de materias primas, sólo que esta vez, las cantidades son exponencialmente mayores.

Los grandes momentos económicos y los booms del capital con sus enormes movimientos de personas y mercancías, a través de sus ciclos, dejan intersticios donde se cuelan actividades del crimen organizado. En estos grandes vacíos, por negligencia o complicidad, se filtran ocultos el contrabando y el tráfico, la prostitución y la trata, el homicidio y el sicariato. Estos constantes y cuantiosos movimientos a escala global inciden, como es lógico, fuertemente tanto en el territorio, como en la sociedad de las ciudades-puertos y sus respectivos hinterland.

En aquel entonces, comienzos del siglo XX, las similitudes entre Chicago y Rosario surgieron en principio, por una cuestión de exportación de granos hacia el continente europeo, pero pronto se encontrarían semejanzas de otra índole; la mafia del crimen organizado se abría espacios en la historia de ambas ciudades y países. Tanto Argentina como los Estados Unidos a fines del XIX y principios del XX habían promovido la inmigración europea, entre ellos italianos, españoles, anarquistas, judíos, rusos, franceses, polacos. Los migrantes europeos de esta época eran radicalmente diferentes a los del periodo migratorio colonial, fundamentalmente porque este 
periodo estaba compuesto por campesinos que huían de la miseria en la que vivían en su continente natal. Los migrantes llegaban al nuevo mundo con deseos de establecerse y ser parte de este nuevo territorio y destino, de recomenzar un nuevo proyecto. Por el contrario, en la época de la conquista, los recién llegados europeos formaban parte de un grupo más reducido y homogéneo con poder económico, donde el imaginario era siempre el generar riquezas rápidamente y retornar a la vieja Europa.

Entre los años 1880 y 1920, encubiertos y disimulados en los grandes contingentes que llegaban a las "Américas", viajaban algunos de los que con el tiempo se convertirían en los más notables gánsteres. En Rosario, será representativo el caso de Juan Galiffi, apodado "Don Chicho" o "Chicho Grande". Este capo, si bien había migrado a la Argentina, siempre mantuvo contactos con la mafia siciliana, de donde eran sus paisanos. Contemporáneamente, en los Estados Unidos el gran "capo mafia" era Alphonse Capone, "Al Capone" o "Scarface" de paisanos napolitanos. Capone, fue un gánster mundialmente conocido por sus historias pero también por el poder mediático "hollywoodense". El gran capo, hasta ser capturado por el FBI se encargaría de sembrar en la ciudad de Chicago la impronta de su sello mafioso personal. Estos personajes inauguran un imaginario criminal que aún persiste en las respectivas ciudades.

Estas circunstancias, dan pistas de alguna manera, acerca de por qué el caso de Rosario se ha vuelto tan significativo y hasta paradigmático en torno al establecimiento del crimen organizado. En este contexto, la geografía urbana pasa a ser el escenario, donde el dinero captado, tanto de forma legal como ilegal va a desarrollar una ciudad profundamente desigual, fiel reflejo de estos procesos. Antes el Boulevard Oroño y el parque Independencia, un siglo después con la posibilidad de trasladar y descentralizar el obsoleto puerto, surge el necesario cambio de escala del capital, y se genera el "balcón hacia el río", y junto con ello, el mega negocio en torno a la especulación inmobiliaria que posibilita el nuevo vacio de carácter "estratégico".

La grave situación actual de Rosario, como podemos ver, no surge ni por primera vez, ni es inexplicable. Sino que es relacional e inherente a las decisiones políticas de someter a la ciudad bajo las lógicas y necesidades del capital. Para que esta gran maquinaria funcione, los diferentes niveles de gobierno, a pesar de su desigual color político, junto con el sector privado, oligárquico, monopólico, latifundista y multinacional debieron articular decisiones. De manera contraria no existen tales posibilidades de éxito.

Sintetizando, la aproximación a la que podemos llegar en estas condiciones, es que en este contexto, la lucha contra el narcotráfico es parte solamente de un show que se profundizará más 
adelante. Por último, cabe resaltar, que las sociedades explicitas o virtuales entre los sectores públicos y privados imponen este devenir, estableciendo un muy difícil e indefinido límite entre las zonas de lo legal y lo ilegal; sucede que finalmente para esta maquinaria obtener el mayor lucro, es el último y único fin.

\section{ESCALA NACIONAL: LA CIUDAD, EL TERRITORIO Y LAS MATERIAS PRIMAS}

El 25 de mayo de 2003 Néstor Kirchner asume la presidencia de la Argentina, sucediendo al gobierno interino de Luis Eduardo Duhalde. El país venía de una larga recesión por lo que para reactivar la economía, el presidente interino devalúa la moneda y con esto, se da fin a la Ley de Convertibilidad $^{3}$. Esta decisión alienta a la actividad económica local que se vuelve competitiva en los mercados internacionales mediante el devaluado peso argentino. Se vislumbran buenos tiempos para el comercio agroexportador acompañado por una leve reactivación de la industria nacional.

El mercado internacional de las exportaciones de recursos naturales, no sólo en la Argentina, sino también en otros países de la región es alentado a partir del desbocado consumo de los países asiáticos como China e India. Para el caso específico de Argentina en especial la agroindustria sojera, aunque también es necesario señalar el crecimiento exponencial del mercado extractivista minero. El balance de la década, claramente demuestra, que el sistema global benefició al nuevo gobierno (Svampa, 2006).

La ciudadanía tenía muy presente la década neoliberal transcurrida de ajuste en ajuste, que había finalizado con el estallido de la crisis en diciembre de 2001. La gota que había derramado el vaso había sido el "corralito bancario" impuesto a los ahorristas que habían confiado en los bancos, pero la presión social generalizada respondía a años de injusticias, corrupción y burla a las grandes hordas de desocupados, pobres e indigentes y a la sociedad en su conjunto. La confianza en las instituciones se había esfumado.

El sostenido y creciente ingreso económico se debe en gran medida a lo que los politólogos Ilaman "viento de cola", que no es más que el beneficio que el gobierno ha obtenido por parte del mercado mundial fundamentalmente a través del aumento récords de las materias primas (Giarraca, 2008; Svampa, 2011). Esto ha permitido una reestructuración nacional, como también

\footnotetext{
${ }^{3}$ Ley de Convertibilidad del Austral (Ley № 23.928), popularmente conocida como "el uno a uno" un peso argentino igual a un dólar estadounidense. La Ley se puso en vigencia en 1991cuando Menem iniciaba sus presidencias. El Ministro de Economía era Domingo Caballo. La Ley permaneció hasta 2003.
} 
de la región. Pero si comparamos a la Argentina con el resto de los del cono sur, veremos que la evolución del PIB no es excepcional, inclusive quedando por debajo del resto.

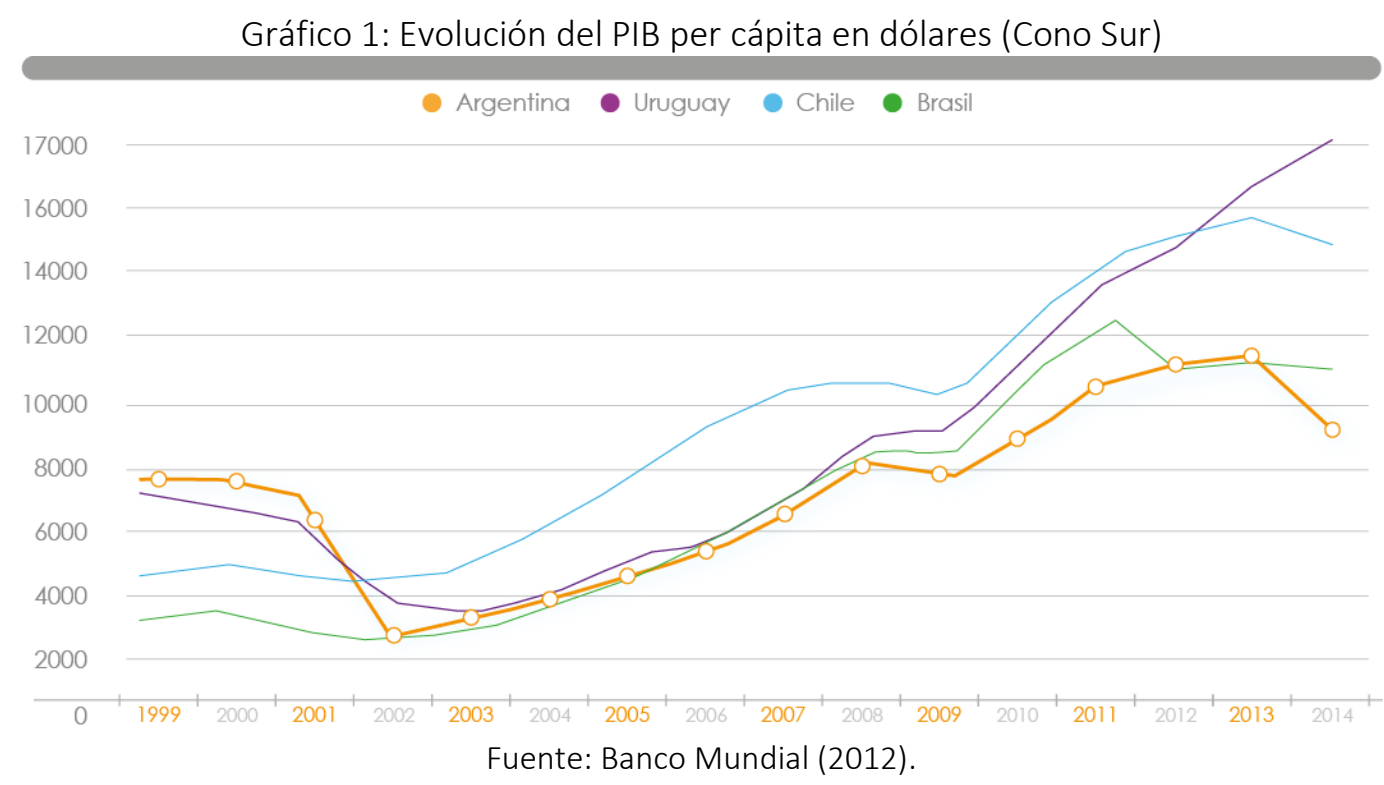

Tras asumir el rol mundial de reprimarización de la economía, los países latinoamericanos denominados progresistas- se vuelven altamente vulnerables debido al peligroso y problemático modelo de sumisión y dependencia (González Casanova, 2009). Por tal motivo, los riesgos pueden ser y en muchos casos son trágicos. Esta vulnerabilidad posee dos sentidos, la primera las gravísimas consecuencias ambientales, la segunda que gran parte de su economía depende del valor internacional de los commodities quedando de esta manera, sometidos a los vaivenes del inestable mercado mundial. Por ejemplo, Ecuador sufre gravísimas consecuencias en este sentido a partir de la caída del precio del petróleo a hacia fines de 2014.

El ejemplo del puerto de Rosario (ENAPRO), el más importante cuantitativamente del país (70\% de las exportaciones), nos corrobora la hipótesis desarrollada más arriba: el 99\% de las exportaciones de productos que egresan por este sistema de puertos están compuestos por productos primarios y de manufacturas de origen agropecuario (MOA). Las manufacturas de origen agropecuario representan el $47 \%$ de las exportaciones y son de elaboración simple y rústica: aceites, alimentos para animales, entre otros; mientras que los minerales y granos en bruto representan el 52\% de lo exportado. En cambio, las manufacturas de origen industrial representan sólo el $1 \%$ de los productos de exportación. Se supone que Argentina es de los países más industrializados de la región. ¿Qué sucederá en nuestros países cuando las materias primas dejen de ser un negocio fabuloso y en alza? 


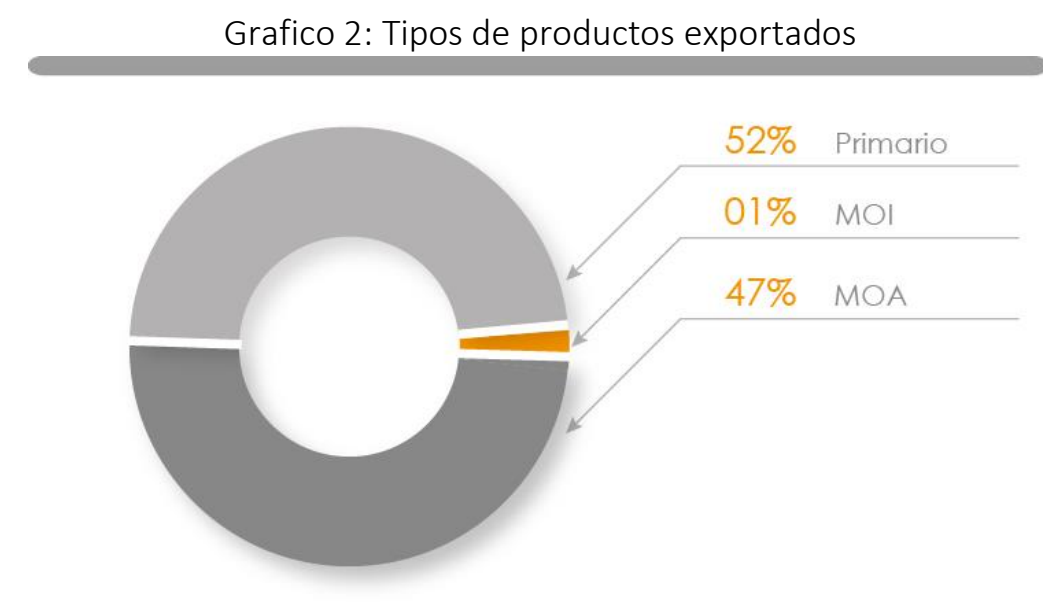

Fuente: Bonomelli, Graciela y Galaverna, Daniel. Pág. 61 (2011).

El modelo extractivo nos remite al rol colonial de América Latina (Quijano, 2000), a un sistema mundo capitalista cada vez más agresivo (Wallerstein, 1989), donde la región es la que provee materias primas, arrasando el territorio. En cambio los beneficios mayores quedan en manos de las empresas multinacionales portuarias y extractivas, y particularmente en el caso de la agroindustria en manos de los grandes latifundistas, también de las élites locales que se suman al juego mediante grupos anónimos organizados a través de "pools de siembra" o "fideicomisos sojeros". Los distintos niveles de gobierno ofician de gestores para que la maquinaria capitalista funcione. En este sentido, Seoane enfatiza:

Es necesario entender que hay una continuidad del proyecto del neoliberalismo en América Latina. El neodesarrollismo actual latinoamericano reposa en la profundización del extractivismo, a diferencia de lo que fue parte del debate sobre el desarrollo en América Latina en la década del 50, donde desarrollo era sinónimo de industrialización, y era contrario a la reprimarización de la actividad económica, o de la consolidación de un patrón de exportación de materias primas al mercado mundial (Seoane, 2013).

Los números de producción y exportaciones sojera de la tabla 1 y 2 respectivamente, con datos entre 2003 y 2013 no parecen dar cuenta de la férrea oposición entre el sector del campo y del gobierno nacional, los números más bien indican una ecuación de sociedad que ha obtenido grandes beneficios mediante el modelo agroexportador. Para ambos sectores esta década ha sido un período de extraordinarios excedentes. Los puertos privados tanto de capitales nacionales o internacionales, con salida global, son claves para la economía del país, así lo rotula Carlos Reboratti: "las fábricas de aceite en grandes plantas generalmente de capitales nacionales [hay alrededor de 50], mientras que los canales de exportación quedaron en manos de las clásicas 
firmas internacionales de comercialización de granos, como Dreyfus, Cargill o Bunge y Born" (Reboratti, 2010).

Tabla 1: Aumento de producción de soja 2003-2013

\begin{tabular}{|c|c|c|}
\hline Campaña & $\begin{array}{l}\text { Producción } \\
\text { de soja (tn) }\end{array}$ & Diferencia \\
\hline $2003 / 2004$ & 31.576 .752 & 31.576 .752 \\
\hline $2004 / 2005$ & 38.289 .742 & \multirow{8}{*}{$\begin{array}{l}\text { Crecimiento de la } \\
\text { producción } 18.423 .242 \\
\text { toneladas }=60 \%\end{array}$} \\
\hline $2005 / 2006$ & 40.537 .636 & \\
\hline $2006 / 2007$ & 47.482 .786 & \\
\hline $2007 / 2008$ & 46.238 .087 & \\
\hline $2008 / 2009$ & 30.989 .469 & \\
\hline $2009 / 2010$ & 52.676 .216 & \\
\hline $2010 / 2011$ & 48.878 .771 & \\
\hline $2011 / 2012$ & 40.100 .197 & \\
\hline $2012 / 2013$ & 50.000 .000 & 50.000 .000 \\
\hline
\end{tabular}

Fuente: Ministerio de Agricultura, Ganadería y Pesca (MINAGRI). Publicado en: agrositio.com (2013).

Tabla 2: Aporte de dólares por exportaciones del complejo sojero 2003-2013

\begin{tabular}{|c|c|c|c|c|c|}
\hline 2003 & $\begin{array}{l}\text { Aceite } \\
\text { (Mill U\$S) } \\
1.935\end{array}$ & $\begin{array}{l}\text { yal Harinas } \\
\text { (Mil uss) } \\
3.209\end{array}$ & $\begin{array}{c}\text { 81 Grano } \\
\text { (Mill uss) } \\
1.813\end{array}$ & $\begin{array}{c}\text { Biodiesel } \\
\text { (Mill U\$S) } \\
-\end{array}$ & $\begin{array}{c}\text { Total } \\
\text { (Mill uss) } \\
6.957\end{array}$ \\
\hline 2004 & 2.135 & 3.562 & 1.726 & - & 7.423 \\
\hline 2005 & 2.060 & 3.780 & 2.264 & - & 8.104 \\
\hline 2006 & 2.620 & 4.342 & 1.769 & - & 8.731 \\
\hline 2007 & 4.135 & 5.762 & 3.414 & 139 & 13.415 \\
\hline 2008 & 4.230 & 7.053 & 4.809 & 878 & 16.970 \\
\hline 2009 & 3.130 & 8.014 & 1.644 & 913 & 13.701 \\
\hline 2010 & 3.954 & 7.237 & 4.937 & 1.224 & 17.352 \\
\hline 2011 & 4.755 & 9.389 & 5.221 & 2.087 & 21.452 \\
\hline 2012 & 4.166 & 9.721 & 3.157 & 1.774 & 18.818 \\
\hline 2013 & 5.100 & 12.000 & 3.900 & 2.000 & 23.000 \\
\hline
\end{tabular}

Total de ingreso de dólared por exportaciones compl. sojero (U\$S) 155.923 Fuente: datos del Instituto nacional de Estadística y Censos (INDEC). Publicado en: agrositio.com (2013). (*) Estimativo 
Esta conjunción de aumento de producción con aumento del precio, posibilitó que el país pasara de exportar por el complejo sojero de 6.957 millones de dólares en el año 2003 a los actuales 23.000 millones de dólares. Si sumamos los 11 años de exportaciones [Tabla 2] el complejo sojero aportó 155.923 millones de dólares (Roulet, 2013).

Los millones de dólares anuales, que como se aprecia en la tabla 2, aumentan año a año, son invertidos en las ciudades mediante construcciones de carácter especulativo como demostraremos más adelante. La ciudad se oferta mediante el marketing urbano para generar recaudación impositiva que sostenga las arcas locales. Los resultados de la inversión localizada dentro de la ciudad, van a aumentar la ya grave desigualdad socioespacial. A escala nacional sucede algo similar, el manto transgénico verde de la soja va a generar una profunda alteración del territorio. Los graves cambios en este sentido, parten desde un desplazamiento demográfico reforzando una muy difícil migración campo-ciudad, totalmente irónica y sin sentido, teniendo en cuenta la grosera desproporción demográfica del país, pasando por una desertificación y contaminación del suelo, desforestando los montes naturales, produciendo inundaciones regulares pero, finalmente logrando el objetivo cardinal, generar el máximo plus valor.

Gráfico 3: Primer cuatrimestre de cada año 2004/2013. Cantidad de metros cúbicos de hormigón para la construcción.

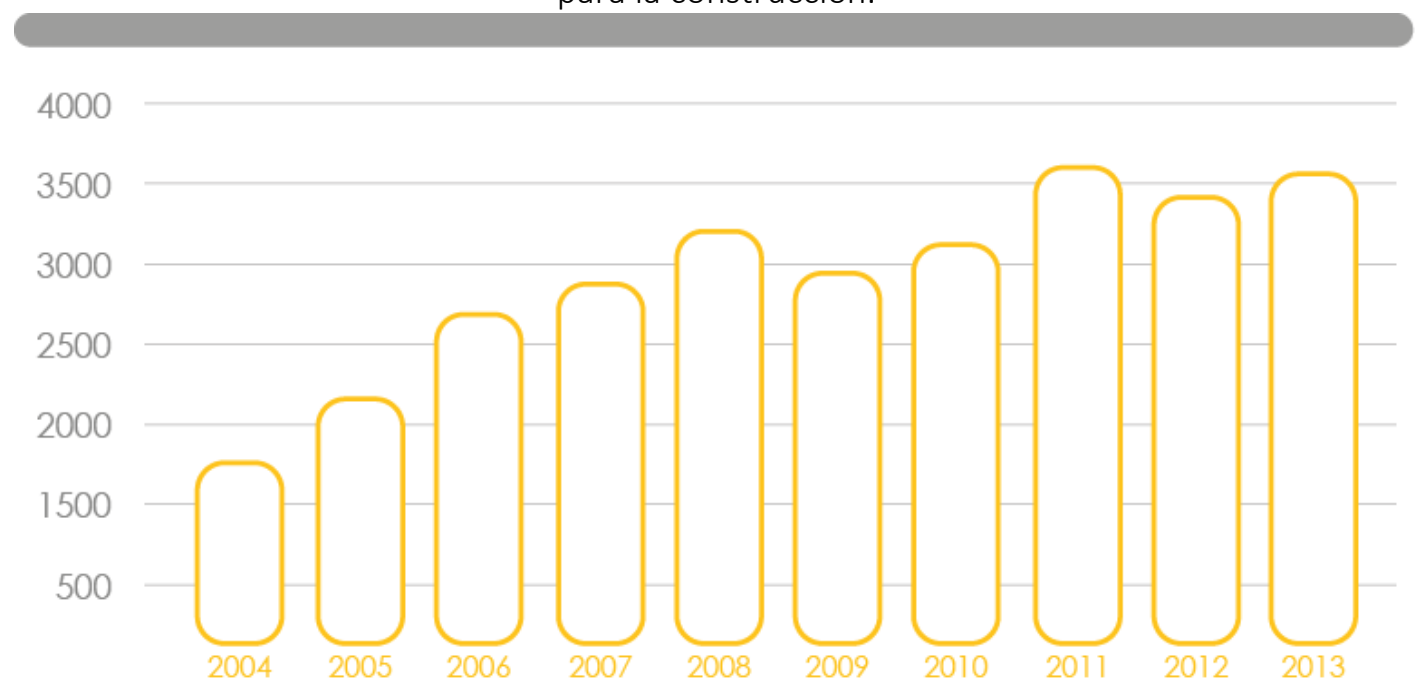

Fuente: datos del Instituto nacional de Estadística y Censos INDEC (2013). 
Gráfico 4: Puestos de trabajo en relación de dependencia del sector construcción, promedio trimestral en miles.

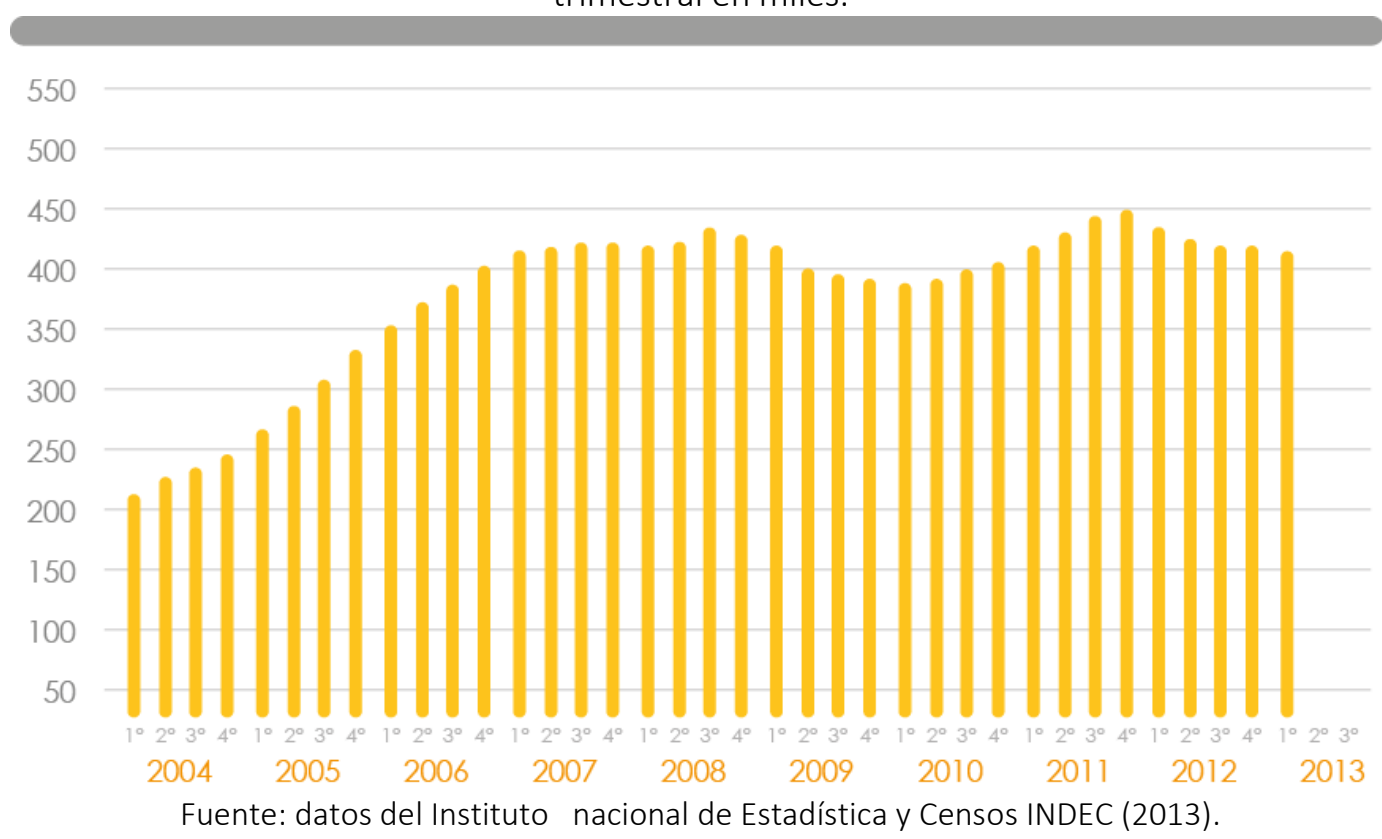

Para validar estas afirmaciones, los números de las tabla 1 y 2 que evidencian el crecimiento de la producción sojera, al ser comparadas con los gráficos 3 y 4 que describen el crecimiento del sector de la construcción, se puede demostrar como el excedente sojero posee una relación directamente proporcional con el sector de la construcción, que adicionalmente, se trata de una construcción que en altos porcentajes es de carácter especulativo.

\section{ESCALA LOCAL: LA CIUDAD, EL ARQUETIPO Y LA INDIFERENCIA}

El 10 de diciembre de 2003 el Ingeniero Miguel Lifschitz asume la intendencia de la ciudad de Rosario, año coincidente con la asunción en el mes de mayo, del presidente argentino Néstor Kirchner. El intendente Lifschitz en aquel entonces, hoy nuevo gobernador de la provincia de Santa Fe, va realizar un giro significativo con respecto a su predecesor, el médico Hermes Binner, ambos pertenecientes al Partido Socialista (PS). Lifschitz se acerca enérgicamente al poder económico local, a la Bolsa de Comercio de Rosario, a los empresarios locales más importantes, a los desarrolladores inmobiliarios y al sector capitalista en general.

El nuevo intendente tenía muy claro cómo captar los excedentes que se estaban generando a partir del modelo extractivo nacional. Para lograrlo era necesario promover la ciudad como escenario de capitalización y territorializar el flujo líquido del dinero, en el suelo rosarino. Esta manera neoliberal de comprender la ciudad se denomina empresarialismo urbano. En una 
entrevista realizada a María Eugenia Bielsa, opositora política del gobierno local, explicaba lo siguiente: "sí, hubo un cambio para mi brutal desde la gestión de Binner que fue más mesurado respecto de la gestión de Lifschitz, por dos cosas a mi juicio, porque Lifschitz, [i] se enamora del establishment, o sea un tipo que encuentra una cosa de relaciones con los sectores del establishment de Rosario [...] y [ii] pone como secretaria de Planeamiento a Mirta Levin [...] con una enorme iniciativa, te diría, casi desmedida" (Bielsa, 2013, entrevista).

En la cita anterior se hace referencia a la secretaria de Planeamiento Mirta Levin (20032011). La arquitecta fue la notable figura que se va a encargar de reestructurar todo el andamiaje legal y técnico para llevar adelante la ambiciosa renovación de los sectores estratégicos de la ciudad. Entre los cuales se puede mencionar los acuerdos públicos privados para el desarrollo de urbanizaciones, como también los convenios urbanísticos. Pero además va a desarrollar una labor descomunal desarrollando un plan urbano para toda la ciudad donde se pueda aplicar la figura del mayor aprovechamiento urbanístico, es decir, en palabras simples, el municipio permite construir más altura de la establecida para que se tribute más a las arcas municipales. La lógica de la recaudación impositiva va a establecer un fuerte vínculo, y a la vez dependencia, con los desarrolladores inmobiliarios y las empresas constructoras.

La Planificación Estratégica fue impuesta y adoptada en América Latina como un sistema que permite a los Estados locales generar recursos económicos, el giro se da en los noventa del siglo pasado con el auge neoliberal cuando el Estado nacional se contrae y desfinancia a los gobiernos municipales. En ese sentido, Carlos Vainer, investigador carioca, en el año 2000 expresaba que existía un pequeño grupo de ciudades "intentando ser globales" de la que Barcelona era el "modelo". Vainer advertía los riesgos del "pensamiento único" que se instala en la ciudad de la mano de la Planificación Estratégica y las consecuencias que puede traer para las urbes y las sociedades "desarrollarlas" a partir de los intereses del sector privado.

O precedente não deve servir, porém, para minimizar as inovações trazidas pela difusão do modelo (pós-moderno?) estratégico. Com efeito, enquanto o modelo modernista a acionava noções e conceitos cuja universalidade parecia inquestionável-racionalidade, ordem e funcionalidade- agora é a cidade, em seu conjunto e de maneira direta, que aparece assimilada á empresa. Produtividade, competitividade, subordinação dos fins á lógica do mercado, eis os elementos que presidem o Harvey chamou de empresariamento da gestão urbana (Harvey, 1996) (Vainer, 2000: 85). 
El modelo Barcelona, o la genérica Planificación Estratégica, trae consigo la difusión de la "imagen de ciudad", con las posmodernas características de competitividad y marketing; esto evidencia que bajo la lógica del sector privado grandes territorios de la urbe quedarán al margen, ya que no serán preferibles a los intereses de los inversores. Bajo este sistema mercantilizado se desarrolla de manera "natural", desde la perspectiva de la racionalidad capitalista, una urbe de dos caras, el resultado urbano y social de hoy, con casi dos décadas de Planificación Estratégica, así lo demuestra.

La lógica de la concentración espacial conduce al desarrollo desigual del espacio. Ciertas zonas del territorio nacional, ciertas zonas de la aglomeración urbana no otorgan al capital las condiciones generales de su valorización: permanecerán inexplotadas. Lo que es cierto al interior de cada país, lo es también por supuesto, a escala del sistema imperialista mundial (Topalov, 1979: 32).

La directiva política local va buscar enfáticamente con los mecanismos del marketing, según el intendente Lifschitz "difundir el contenido del Plan ${ }^{4}$ a todas las organizaciones y ciudadanos de Rosario", bajo el argumento del "consenso" que permita desarrollar de manera pacífica los acuerdos entre las novísimos asociaciones público-privadas. De esta manera se instala el pensamiento único del que hacíamos referencia más arriba, que elimina o anula a los disidentes. En la mesa de diálogo pulula el concepto neoliberal de flexibilización, de modo contrario cabe preguntarse cómo se entendería la afinidad de las empresas privadas que operan mediante su lógica racional de aumentar el capital, junto a los intereses de los muy diversos grupos de ciudadanos, o movimientos sociales. La historia de la ciudad entendida como polis (donde debaten los diversos), ha sido siempre y desde su mismo origen el espacio del conflicto y la disidencia y nunca del consenso.

En el marco de los 10 años de operación de la Planificación Estratégica Rosario (PER), Lifschitz, desde la casa de uno los actores claves de este plan, la Bolsa de Comercio Rosario, expresa en el año 2008 los logros de esta operatoria:

La ciudad de Rosario comenzó a transitar el gran desafío de construir una plataforma de consenso, que le permitiese establecer un horizonte de desarrollo, definido en términos de orientaciones estratégicas y proyectos generadores de cambio. Rosario se propuso formular su Plan Estratégico de ciudad. (...) El PER, como se lo conoce, fue pensado como herramienta que permite generar un proceso en el que se articulan las iniciativas de los actores públicos y privados con el fin de potenciar el desarrollo de la ciudad.

\footnotetext{
${ }^{4}$ Plan Estratégico Rosario (PER), dicho plan urbano es implementado desde 1998.
} 
(...) La aplicación de esta metodología, que provenía del sector privado, para su implementación para escala de ciudad, se encontraba aún en un estadio primario en nuestra región. (...) Las primeras iniciativas, entonces, giraron en torno a instalar en la opinión de aquellos actores representantes del sector económico, social y gubernamental la necesidad que como ciudad teníamos de acordar un proyecto colectivo (...) Todos estos proyectos han tenido, sin duda, un carácter estratégico y pueden ser evaluados a la luz del cambio significativo que han producido, por ejemplo, en el perfil económico productivo de la ciudad (Lifschitz, 2008).

Tras las palabras de Lifschitz, se esclarece porqué el nuevo paisaje urbano irá ciñéndose por un lado, a los barrios privados y cerrados, a las elitistas torres céntricas, a los shoppings centers, a los clubes privados, entre un conjunto de actores "ganadores"; por el otro, de manera relacional, se densifican las villas de emergencia cada vez más grandes y pobres asociadas a la delincuencia y la "vagancia". En definitiva, el espacio construido no es más que la evidencia del modo de producción de una sociedad. Por consiguiente, la ciudad física y la sociedad urbana se irán fragmentando cada vez más, dejando intersticialmente a una clase media cada vez más constreñida. Las palabras a continuación del historiador urbano Adrian Gorelik nos ayudan a comprender este escenario político global y su enlace con la escala local:

No se trató de un cambio exclusivamente latinoamericano, por cierto, sino el producto de una caída múltiple que se combinó en la coyuntura internacional de los años setenta: la caída de la idea de planificación (arrastrada por la caída conjunta del Estado de bienestar y el socialismo) y la caída de la idea de revolución (que arrastra consigo las figuras de América Latina y de Tercer Mundo). (...) pero ahora en directa sintonía con el debate sobre la postmodernidad y las nuevas posturas urbanísticas que presidían la recuperación urbana europea, posturas que también le daban a la cultura urbana un rol fundamental como clave del éxito de las ciudades en el mercado global (Gorelik, 2006: 18).

Las ciudades en esta trama se han visto extremadamente modificadas. El retiro del Estado que con las dictaduras militares se anunciaba en los 70', se profundizaba en los 80' y definitivamente se termina de contraer en los 90', produce sistemas urbanos cada vez más individualistas y fragmentarios ${ }^{5}$. El derrotero de estas décadas neoliberales somete a la población a viajar en un colectivo sin retorno hacia la tercerización de los puestos laborales, pero cabe resaltar que "esta tercerización está muy alejada estructuralmente de la que ocurre en Europa, Japón o Estados Unidos, y que daría lugar a la sociedad posindustrial. En lugar de un avance hacia una nueva estructura económica, la Revolución Terciaria" (Pradilla, 2008: s/p). Emilio Pradilla afirma que en esta región del mundo la situación es totalmente diferente donde "la tercerización informal

\footnotetext{
${ }^{5}$ Para un análisis de esta cuestión en mayor profundidad ver "Cidade de Muros" de Teresa Caldeira 2007. Editorial GEDISA, Barcelona.
} 
nos está mostrando la incapacidad de la economía urbana latinoamericana para integrar en la estructura formal a toda la fuerza de trabajo disponible, una de cuyas causas es, precisamente, la desindustrialización" (Pradilla, 2008: s/p). El mercado avanzaría sobre los espacios cedidos por el Estado, algunas veces lo haría el sector privado de manera independiente, y algunas otras, en sociedad con el gobierno local reduciendo sus funciones a la gestoría del proceso.

El avance del despojo sobre el territorio queda expuesto cuantitativamente en los siguientes párrafos en una reflexión sobre el parque habitacional, demostrando además, lo que afirmábamos más arriba sobre cómo el excedente sojero se materializó en construcción de carácter especulativo. En una nota a un medio local Patricia Lagarrigue, miembro de la Comisión de Acceso al Suelo, Vivienda y Desarrollo Urbano, expresó que "cerca de 70.000 viviendas ó sea el 17 $\%$ del parque habitacional del área metropolitana de Rosario se encuentra deshabitada". Además, añadió que "Si tenemos en cuenta que los inquilinos, según los datos citados de fines de 2011, tenían un nivel de ingreso 15\% superior a aquellos que eran propietarios de vivienda y del terreno, desde el punto de vista de la accesibilidad social, podemos concluir que la gente tiene los ingresos suficientes para alquilar viviendas pero ellas no se encuentran disponibles en el mercado" (Lagarrigue, 2013). No son viviendas de alquiler, son viviendas de ahorros en ladrillos.

Por un lado tenemos, según lo expresado, 70.000 viviendas vacías ocupando espacio urbano construido socialmente (especulación sobre un patrimonio común: la ciudad), y por el otro, la necesidad de 40.000 viviendas, para aproximadamente un 20\% de la población de la urbe que carece de un único lugar digno para vivir. Las cifras pueden variar según la fuente, se habla de la necesidad de hasta 50.000 viviendas como lo indica en la siguiente cita el mismo (ahora gobernador) Lifschitz, señalando que las viviendas ociosas ascienden a 80.000 unidades. Los números demuestran con contundencia como las políticas han beneficiado la concentración de propietarios para la especulación fruto de la Planificación Estratégica y la mercantilización de la ciudad y que por el contrario no se ha influido significativamente en la solución del parque habitacional. Las palabras de Lifschitz en página oficial del Municipio de Rosario en octubre del 2010, hacen referencia al déficit habitacional:

El intendente estimó que existen unas 25 mil familias de sectores medios que necesitan acceder a una vivienda propia, y en este sentido consideró que 'los actuales créditos hipotecarios no constituyen una solución viable por los salarios que perciben los integrantes de dichas familias'. Lifschitz también calculó en una cifra similar a las familias de los sectores más desprotegidos que deben ser provistas de una vivienda social (Lifschitz 2010). 
La realidad material de la ciudad en el presente deja leer con absoluta claridad el impacto que ha recibido el sistema urbano con las políticas de exposición de la ciudad en el mercado global. En este sentido, como señala Vainer, la ciudad no es una mercadería más, es sobre todo: "uma mercadoria de luxo, destinada a um grupo de elite de potenciais compradores: capital internacional, visitantes e usuários solváveis" (Vainer, 2000: 83). Lamentablemente, las caras totalmente contrapuestas de la urbe exponen con violencia las consecuencias de este modelo neoliberal de entender y producir ciudad como mercadería de lujo. El concejal rosarino Alberto Cortés se detiene en describir la contracara de la Planificación Estratégica:

El abandono de los barrios no se limita a las problemáticas de obras y servicios públicos, sino que se extiende a las políticas sociales, donde el hecho de que en los últimos años casi todos los conflictos gremiales en el ámbito municipal han tenido que ver con la precarización de los trabajadores de estas áreas, como ser salud o la desorientación en materia de políticas de promoción social (Cortés, 2013, entrevista).

Estas palabras ponen énfasis en el entorno real en la que se levanta día a día la mayor parte de la población de la ciudad, otorgando pistas que permiten comprender la situación actual de la ciudad; desde una perspectiva espacial: abandono de los barrios y desde una perspectiva social: precarización y falta de recursos. La violencia desatada en estos últimos años en la ciudad de Rosario no surge de manera aislada a toda esta realidad histórica, geográfica y material en la que se encuentra la ciudad desde hace ya décadas. Por el contrario, se explica a través de éstas. Asimismo, queda claro que los barrios marginales son una de las caras de la acumulación desigual, resultado de la deliberada elección política en la que se yuxtaponen en una sinergia perversa: extractivismo, Planificación Estratégica o venta de la ciudad y narcotráfico, generando un denso coctel urbano soberanamente desigual y como no podía ser de otra manera: extravagantemente violento. El premio de todo esto es la ya famosa postal de la urbe sobre el río, lugar donde se articulan posiciones estratégicas, hiperconcentrando ganancias. La desigualdad socioespacial generada sobre el territorio es violenta y homicida sin necesidad de manipular ni contar cadáveres.

\section{ESCALA BARRIO: LA CIUDAD, LA VIOLENCIA Y LOS PUERTOS}

Por los puertos pasan miles de toneladas de materia prima sin procesar, y si en la ciudad se invierten y solapan los excedentes de los negocios legales e ilegales, en los puertos se solapan y disimulan las mercancías. Los mercados legales e ilegales buscan hacer llegar a sus compradores transoceánicos sus servicios. Como revela el periodista y diputado electo Carlos del Frade, estos productos, en su paso van dejando efectos en la población. El autor resalta el título y encabezado 
de la ácida Revista Barcelona: "Soja o merca". En su edición 293, la revista aborda el tema con una discusión polémica:

¿El boom de la producción sojera cede paso al boom de la producción narco? Los modelos de crecimiento con inclusión y muerte que proponen Monsanto y Sinaloa, ¿son opuestos o complementarios? Los argentinos, ante la necesidad de definir sus próximas décadas en torno al modo en que preferirán intoxicarse y morir. ¿Niños con malformaciones a causa del glifosato o cadáveres decapitados a causa de la guerra narco? (Del Frade, 2014: 429).

La "soja o la merca" tienen mucho en común y marchan juntas, pero antes de embarcarse hacia sus destinos dejan sobre el territorio el lamentable resultado multicolor: habitantes rurales envenados por la verde soja, los urbanos por el blanco polvo y la ciudad por el rojo ladrillo color especulación inmobiliaria. Los puertos son claves, precisamente, en la circulación del capital, representan el lugar donde se puntualiza el mayor ingreso económico a las arcas nacionales por ser el lugar específico donde se concretan y fiscalizan las retenciones al agro, particularmente a la soja, por lo que es lógico que deberían tener un riguroso control, Del Frade, continúa:

Capitalismo puro. Negocios que se hacen desde arriba hacia abajo. Un ex comisario de la policía federal [en 1998] a cargo de la delegación de Drogas Peligrosas, Oscar Álvarez, se animó a decir que la mayoría de la droga entraba y salía por los puertos privados del Gran Rosario. Recién en el año 2013, la Auditoría General de la Nación confirmó aquello con un informe que destacaba la ausencia de verificaciones en los puertos de Buenos Aires, Ramallo, San Nicolás, Rosario, San Lorenzo y Puerto San Martin. Y hasta la interesada DEA marcaba la región, a principios del tercer milenio, como uno de los más importantes lugares por donde pasaba gran parte del flujo narco por el continente y rumbo a Europa (Del Frade, 2014: 13).

El puerto o los puertos de los que venimos hablando, en realidad abarcan más de 150 kilómetros de extensión; si consideramos que hacia el norte se extiende hasta Timbúes a unos 50 kilómetros aguas arriba; y hacia el sur, hasta el partido de Ramallo en la Provincia de Buenos Aires (generalmente no se suele tener en cuenta que el sistema portuario a superado los límites provinciales), donde se encuentra el Parque Industrial COMIRSA (Complejo Industrial Ramallo-San Nicolás), inclusive superándolo varios kilómetros aguas abajo, a más de 100 kilómetros de la ciudad de Rosario.

Su extensión casi continua y su caudal lo convierten en uno de los puertos más grandes del mundo, esta descripción así lo corrobora: "ésta zona es la más importante del país en lo referido a la exportación de granos y subproductos, llegando a representar entre $65 \%$ y $70 \%$ de la exportación física total, siendo mayor en término de valores" (Bonomelli y Galaverna, 2010: 12), eso sin incluir los puertos trans-provinciales de Buenos Aires. En el gráfico 5 se puede apreciar la 
gran mancha verde correspondiente a la región sojera y en puntos amarillos el sector portuario de Rosario. Un vasto y cuantioso territorio a controlar.

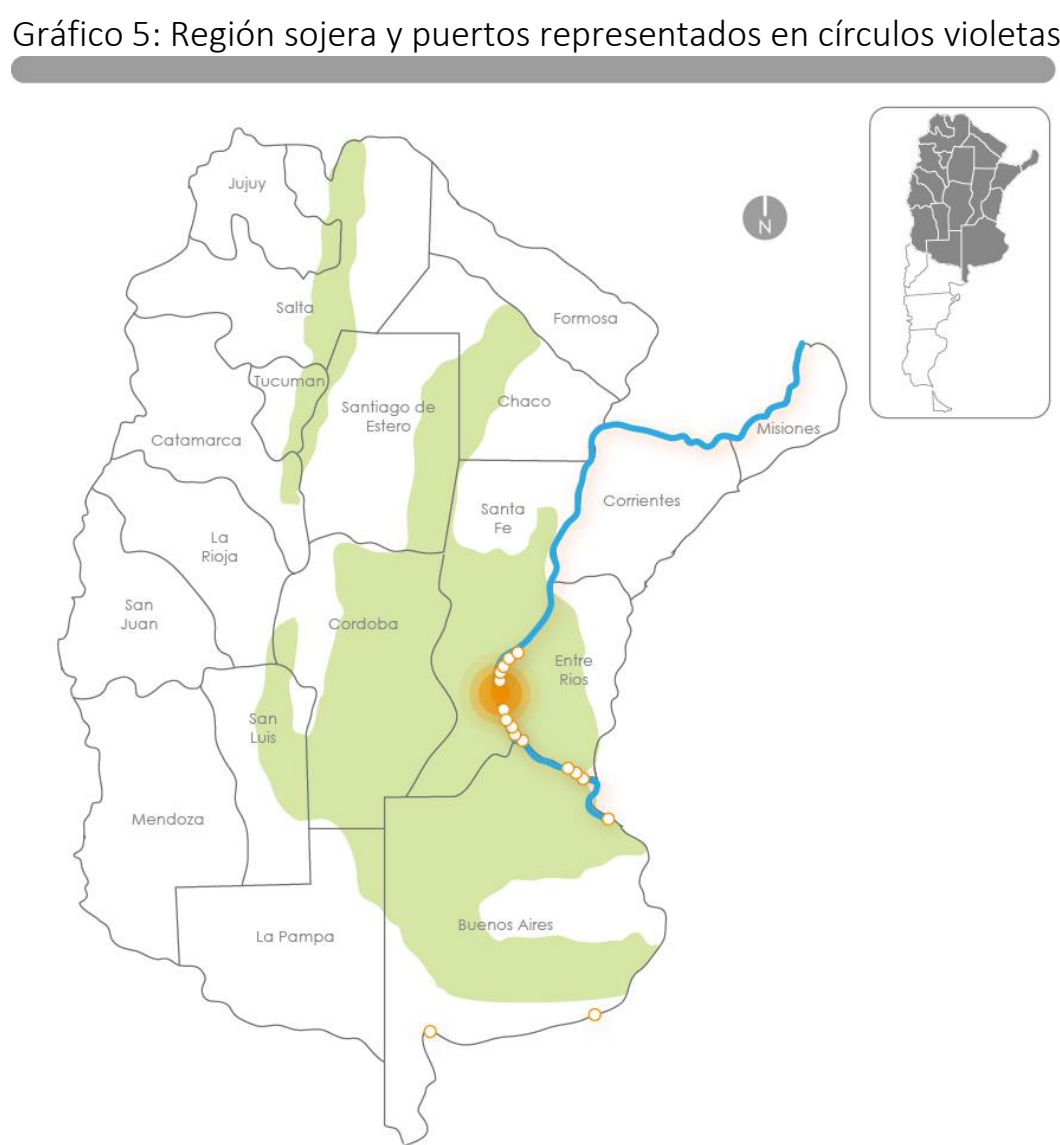

Fuente: http://dx.doi.org/10.4067/S0718-34022010000100005. Revista de Geografía Norte Grande, 45: 63-76 (2010).

La falta de controles en los puertos se complementa por parte de las autoridades con estrategias represivas en los eslabones más débiles de la cadena del narcotráfico, es decir, no se realizan controles en los puertos donde se filtran toneladas de drogas ni tampoco se investiga de dónde proviene, pero sí se reprime a los jóvenes en los barrios más pobres de la ciudad. Edgardo Buscaglia $^{6}$, experto en crimen organizado, señala que las acciones que se están tomando con respecto al narcotráfico en la región (desde México hasta Argentina), son inadecuadas, y desarrolla:

Cuando en España se detiene a una "mula" que esta transportando cocaína en su cuerpo desde Buenos Aires a Madrid, los fiscales de la Audiencia nacional investigan todas las ramificaciones de la empresa que está

\footnotetext{
${ }^{6}$ Su trabajo como asesor en reformas judiciales, prevención y combate del delito organizado, y corrupción pública y privada, cubre desde 1990 a la fecha a 2015, 109 países del mundo.
} 
utilizando a esa persona para el transporte. No se investiga o se reprime, como en la Argentina, sólo a la "franquicia", a los pibes, a los "soldaditos" que están vendiendo al menudeo. Ésas son franquicias y lo que hay que desmantelar son los directorios. Eso es lo efectivo y de nada sirve hacer "el show" de mandar helicópteros a Rosario o Culiacán y desembarcar cientos de soldados. Esto es como tratar de controlar las transacciones ilegales de un banco deteniendo los cajeros (Sierra, 2014: 35).

Por su parte la jueza federal argentina Laura Inés Cosidoy, enfatiza la importancia de seguir la ruta del dinero, y no a los eslabones más débiles del narcotráfico; ya que:

Se maneja mucho dinero, se lava mucho dinero. Me gustaría investigar tantos shoppings acá en Rosario que no venden nunca nada, por qué aparecen, por qué están (...) no sé si está todo acá en Rosario (...) por arriba tiene que haber. $Y$ todo se puede investigar, a todo se puede llegar pero creo que no se quiere. (Del Frade, 2014: 94).

A partir de las palabras de la jueza federal, surge la pregunta si es que además de una alta corrupción policial como ya ha sido demostrado (por ejemplo el caso del ex jefe de la policía de Santa Fe Hugo Tognoli, preso por complicidad con el narcotráfico), no sucede también que ir en contra de los capitalistas de la ciudad que invierten en inmuebles de alto estándar es ir en contra del sistema de recaudación impositiva elegido por el gobierno local.

Recapitulando lo argumentado; se afirma la existencia de un vínculo relacional entre el modelo nacional y el local, y que estos inciden juntos sobre el territorio acrecentado una geografía cada vez más desigual. Ahora bien, la privatización y la pérdida de competencias por parte del Estado sobre el puerto de Rosario trae aparejado el problema de la inseguridad y el control. En este sentido, cabe resaltar que los exportadores de granos y minerales son tan capitalistas como los narcotraficantes; irónicamente lamentable es que el producto ilegal narco tiene mayor elaboración que el producto legal con que la nación se construye. La pregunta que aquí surge es la misma que desarrollamos más arriba, con respecto a la falta de seguimiento del dinero del narcotráfico invertido en la ciudad cla falta de control en los puertos se debe a que fiscalizar es ir en contra de la lógica recaudatoria nacional?

En la búsqueda de insertar a la ciudad en el mercado mundial, el gobierno local describe en varios documentos los beneficios geográficos de Rosario y su zona metropolitana en el Cono Sur, se abunda en descripciones sobre la región de Rosario y su inserción estratégica en el Mercosur. En estos documentos se explican los beneficios de la ubicación central de la ciudad, la región y lo que significa el acceso directo al sistema fluvial del río Paraná con conexión ultramarina. Estas mismas virtudes geográficas para la exportación de las materias primas, sumada al cambio de escala de las múltiples infraestructuras afines, colocaron al puerto de Rosario en el mercado regional y global 
como el gran puerto del Cono Sur. En este contexto tan propicio para la exportación de millones de toneladas de mercancías -y sumado al poco o nulo control de las cargas- Buscaglia revela que "debido al dinamismo de alguno de sus actores y su posición geográfica estratégica, Santa Fe ha sido una de las provincias ideales para que las organizaciones delictivas se establezcan" (Sierra, 2014: 36).

Tal como afirma en Sierra, Claudio Izaguirre, de la Asociación Argentina Antidrogas:

En el país hay ya seis cárteles narcos instalados (...). Todo el este, con los puertos de Rosario, San Lorenzo, Ramallo, etcétera, está controlado por los colombianos; los mexicanos dominan el norte de Buenos Aires y son netos exportadores de cocaína a Europa (...) los argentinos pueden ser los mediadores en todos estos negócios. (Sierra, 2014: 185).

Por los puertos, de comprometido control desde hace ya años, se trafican grandes cargamentos de cocaína hacia Europa ${ }^{7}$. Esta circulación de mercancías ha generado un lucrativo campo laboral para las organizaciones criminales locales, que como se señala en la cita superior han oficiado de mediadores entre los grandes cárteles y los lugares globales de destino. En este proceso, las organizaciones criminales locales no van a ser retribuidas con dinero, sino con porcentajes de mercancías de estos cargamentos, que luego se van a comercializar en el territorio local siendo así, cada vez más fuertes en la lucha por su territorio. Pero en el afán de lograr el control, estas fuerzas territorializadas compiten por el espacio con otras bandas criminales instalando una espiral de diversas violencias. En el año 2013 tras disputas por el territorio de estas organizaciones criminales, acontece un hecho clave en el devenir del crimen de la ciudad, durante la madrugada del veintiséis de mayo asesinan a Claudio "Pájaro" Cantero, líder de la poderosa banda los Mono (Causa de Los Monos).

\footnotetext{
${ }^{7}$ La causa del Carbón Blanco destinaba una tonelada de cocaína hacia Europa. Si bien este renombrado caso no fue embarcado en los puertos de Rosario, sino que aguas más arriba, está preso un importante empresario de la zona relacionado con el futbol local y el Club Barcelona.
} 


\section{Gráfico 6: Homicidios dolosos en el departamento Rosario}

\section{0}

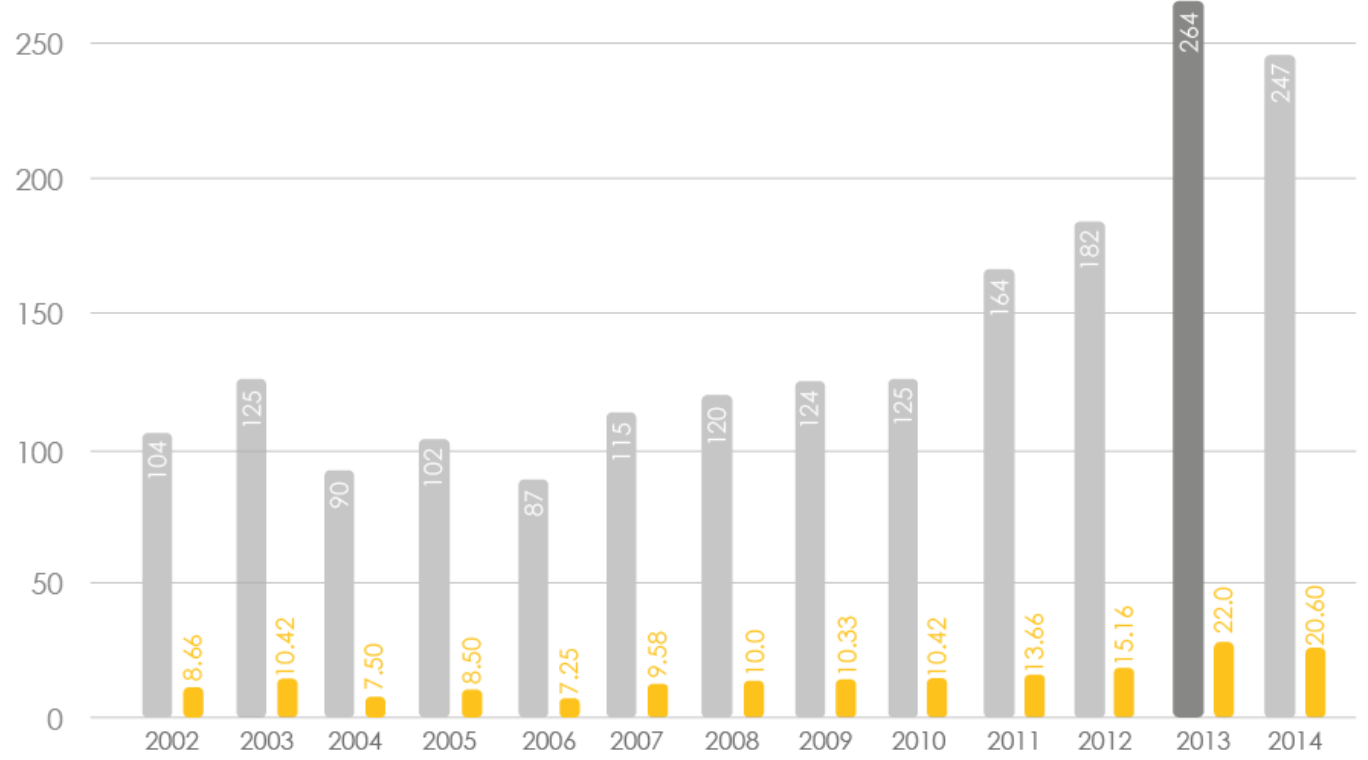

Fuente: Ministerio de Seguridad (2015).

El gráfico 6 expone cómo los homicidios en el departamento de Rosario se han mantenido medianamente regulares hasta el año 2010, acrecentándose drásticamente en los años posteriores, hasta llegar a la crisis del año 2013 con el asesinato de Cantero. Este hecho desencadena un nuevo episodio en la historia de la ciudad, por lo que el nueve de abril del año 2014 "desembarca" en la ciudad la Gendarmería nacional ${ }^{8}$ en un operativo sorpresa con más de tres mil efectivos de la fuerza federal. Dicho arribo es denominado "Plan de pacificación", donde una vez realizado el impresionante sitio militar de la urbe, se establecen con mil quinientos efectivos de manera permanente hasta fines de diciembre del 2014. El retiro de las fuerzas genera intensas agitaciones políticas entre los diferentes niveles de gobierno que además poseen distinto color político. El día 15 de mayo de 2015, sucede el segundo desembarco, las fuerzas de la Gendarmería van a retornar con mil quinientos efectivos, y lo harán con retiro indefinido. Este retorno también trae consigo interminables convulsiones en el sector político, muy cercano a las elecciones de gobernador de la provincia de Santa Fe que finalmente se quedará con un muy

\footnotetext{
${ }^{8}$ Gendarmería Nacional Argentina (GNA), funciona bajo la órbita del Ministerio de Seguridad. Es la principal fuerza del país, su diferencia con las restantes Fuerzas de Seguridad y Policiales (PFA, PNA, PSA y Policías Provinciales), por ser de naturaleza militar, con características de Fuerza denominada de doble empleo: policial y militar.
} 
ajustado resultado en manos del ex-intendente rosarino Miguel Lifschitz. Asimismo, además del refuerzo de la Gendarmería, la provincia crea dos nuevas fuerzas: i) Policía comunitaria, y ii) Policía de acción táctica. El resultado, es que hoy, las calles de la urbe son patrulladas por seiscientos gendarmes y mil doscientos policías provinciales mediante el denominado "Plan de pacificación".

A nivel local, el mismo gráfico 6, demuestra la poca efectividad que ha tenido un año de sitio (2014) sobre la ciudad, sólo bajando 1,2 o 1,4 puntos el índice de homicidios dolosos, según la fuente. Más drástico aún son los índices de la región: "América tiene la tasa de homicidio más alta del mundo (con un valor de 19), seguida de cerca por África (16). Bien lejos están Asia (4), Oceanía (3) y Europa (2) (Ciudades en la encrucijada, 2014; 9). La ciudad de Rosario en 2013, en su vértice más violeto, alcanzó un índice de veintidós (22) asesinados por cada cien mil habitantes, por encima del promedio de América, el continente más violento del mundo. Asimismo, Rosario nunca alcanzó los niveles para estar dentro del grupo de las cincuenta ciudades más violentas del mundo, aunque lamentablemente está muy cerca.

La compleja situación antes descrita es una confirmación de que "nada nuevo brilla bajo el sol". En América Latina, el Plan Colombia (o "Plan para la paz") suscrito por Colombia y los Estados Unidos en 1999; el Plan Mérida o Plan México pactado en 2008 también con los Estados Unidos; y a fines de ese mismo año, con esta misma lógica de pacificación, el secretario de Seguridad de Río decide "pacificar" las favelas de su ciudad instalando "Unidades de policía pacificadora (UPP)". Los resultados en estos países señalan que la guerra contra el narcotráfico, en estos términos, está absolutamente perdida. En este sentido, desde hace varios años, más de cuarenta ciudades de las cincuenta ciudades más violentas del mundo son latinoamericanas, cuarenta y tres en 2014, concentradas mayormente en Colombia, México y Brasil donde se aplicaron los planes de "pacificación" (Forbes México, 2014). En este contexto, los eminentemente perjudicados son los civiles que quedan atrapados en medio de la beligerancia "pacificadora" que convierte a sus barrios en escenarios de batallas, donde además, son quienes ponen a los muertos, y que por otro lado, esto también ha servido para desplazarlos de sus territorios cuando así lo ha deseado el capital. La brutal desigualdad montada no se apacigua con más balas. Los modelos del gobierno nacional y local han producido monstruos como ya lo vaticinaba Harvey en 1973, donde también intuía un período de intensos conflictos que podían ser violentos dentro del sistema urbano. Desdichadamente, el geógrafo tenía toda la razón. 


\section{CONCLUSIONES}

La superposición de las tres variables expuestas al inicio del artículo: región más desigual, violenta y urbanizada del mundo, una vez que se establecen sobre el territorio, indefectiblemente relacionadas, generan el espacio propicio para que los intereses de máxima rentabilidad del capital prosperen. Pero en verdad, la ecuación es al revés, las políticas aplicadas sistemáticamente desde hace más de cuarenta años en la región generaron estos lamentables récords. Además, esto sucede sin el freno de las organizaciones sociales puesto que estas son drásticamente debilitadas en pos de lograr el artificioso "consenso". Los intereses de máxima rentabilidad no diferencian entre ganancias legales e ilegales, acorde a los tiempos posmodernos donde la estética del capital se impone sobre cualquier impronta de la realidad que no tenga por fin el lucro. La imagen domina por sobre la forma y la función y se crea la superficial estética del poder.

En este sentido, los mercados legales extractivistas y neocoloniales utilizan la ciudad formal construida socialmente como receptáculo de sus excedentes creando la nueva imagen del poder. Se consolida de este modo la imagen global de la urbe, su postal de diseño a la moda donde se goza "calidad de vida". El costo es altísimo, en la escala local, la ciudad practica procesos de gentrificación, fragmentación y polarización socioespacial, además, y como es lógico, se deteriora la "calidad de vida". El campo, en la escala regional, es vaciado por la desertificación tóxica, donde además, el nuevo cultivo es genéticamente modificado asesinando mediante la razón científica a la pampa húmeda por un homogéneo y extenso desierto que, irónicamente, cuando llueve se inunda. De esta manera, se puede comprender el éxito del proyecto de la ilustración -la naturaleza dominada para la supervivencia del capital- y no de las personas.

Por otro lado, de manera complementaria a la mercantilización institucionalizada, a la legalmente respaldada por el Estado, se desarrollan sinérgicamente los mercados ilegales. Esta sinergia se explica en sí misma por lo expresado anteriormente, afirmando que en este sistema abstracto sin ética, "el dios", por sobre todas las cosas, es la máxima rentabilidad. La humanidad a fuerza de razón, de ciencia positivista y de control represivo estatal se ha puesto al servicio de este único fin. Entonces, bajo esta ley universal, no existe manera posible de frenar el fructífero y lucrativo mercado de las drogas. Esto explica porqué el tráfico y su excedente económico son la otra gran fuente de recursos que se aprovechan de la urbe para "blanquear" el dinero producido por el tráfico de drogas. 
Ahora bien, en la contracara de la imagen ganadora producida en el sector más codiciado y estratégico de la urbe, donde se vende y consume la calidad de vida, se puede apreciar la otredad dialéctica no ganadora, y es aquí donde podemos ver nuevamente la sinergia que propone el poder del mercado desregulado. Donde la ciudad no va a recibir los excedentes económicos del sistema y, donde además, el Estado, entre vaivenes, retrocede. Aquí, en las periferias, la violencia prospera y también se genera una "otra" imagen y cultura. En estas amplísimas áreas de la urbe, donde las políticas neoliberales licuaron identidades obreras generación tras generación, y donde laten deseos de pertenecer, la oferta laboral es pasaporte de acceso a la estética de este "otro" lado de la urbe.

En este duro contexto social el ideario construido y la posibilidad más cercana y constante es la de ser parte de alguna banda de narcotraficantes que permitan acceder a los objetos de deseo y pertenencia. Sobre todo, cuando tenemos en cuenta que estas décadas no no han estado en un período economicamente deprimido, sino que por el contrario han sido tiempos cada vez más marcados por el consumo, o por las espectativas que se generan detrás del consumo. Estas cuestiones culturales inducidas por el mercado (para todas las clases sociales) evidencian las desigualdades y los desiquilibrios dolorosos en el que día a día se levantan los niños y niñas de la ciudad.

Todas las historias confluyen en el puerto, denominador común, símbolo y razón de la ciudad de Rosario. El barrio Refinería y Puerto Norte crean durante el transcurso del siglo XX la identidad ciudadana en torno a las actividades ferroportuarias. Una centuria después, al comenzar el nuevo milenio, estos espacios profundamente identitarios son devorados bajo la lógica de la regeneración urbana mercantilista creando la nueva cara posmoderna y global de la urbe, pero esta vez, sin "personalidad" homogeneizada e intentando ser global.

Los nuevos puertos creados, ahora en manos de las multinacionales, reemplazan al antiguo, desarrollándose a lo largo del Paraná por más de 150 kilómetros. De esta manera el salto de escala, como es natural, genera profundos cambios y conflictos en la geografía del territorio de las pequeñas poblaciones y ciudades donde los puertos se asientan. En esta disputa queda claro quién pierde, los respectivos gobiernos locales aceptan los "beneficios" del gran capital con el discurso del "progreso" y los habitantes pierden medioambiente y la renombrada "calidad de vida". El fin primordial es siempre el mismo, que estos nuevos puertos que exportan al mundo millones de toneladas anuales de cereales y minerales sigan inundando de materias primas a las 
regiones más remotas del orbe, donde además se cuelan demasiado fácilmente en sus inconmensurables volúmenes miles de kilogramos de cocaína.

Las multinacionales y el crimen organizado, sumada a la negligencia o complicidad de los diferentes niveles de gobierno que ofician de gestores del capital privado alimentan el sistema, en amplio espectro, para el consumo capitalista. No para construir casas para gente que no tiene techo, ni para generar alimentos para gente que no tiene comida, el fin es siempre que la maquinaria mundial no se detenga. Cabe finalmente preguntarse cuál será la nueva y diferente economía política que se podrá aplicar para salir de este círculo vicioso insostenible, devastador y monopólico del que se alimenta el sistema capitalista global. Así, queda claro, que este modelo entre la crisis económica o la crisis medioambiental elige seguir devastando el territorio, y que así lo hará hasta su mismísimo fin. Por último, deseo resaltar, que esta descripción de la realidad de la ciudad, el país y la región no es solamente para entenderla, sino para cambiarla.

\section{BIBLIOGRAFÍA}

ALGRANATI, Clara y Seoane, José (2013). La ofensiva extractivista en América Latina. Crisis global y alternativas. Revista Herramientas № 50, América Latina, Ediciones Herramienta. http://www.herramienta.com.ar

BARENBOIM, Cintia Adriana (2013). El mercado de suelo y su ordenamiento en la periferia de las ciudades: el caso de Rosario, Argentina. - 1a ed. Teseo - Ciudad Autónoma de Buenos Aires.

BONOMELLI, Graciela y Galaverna, Daniel (2011). El puerto de los rosarinos. Potencialidades y Perspectivas. Análisis de la actividad económica del Puerto de Rosario y su movimiento. Cuadernos del IEU, UNR2020 №2 - ISSN 1853-6751.

CALDEIRA, Teresa (2011). Ciudad de Muros. GEDISA. Venezuela

CORTÉS, Alberto (2013). Generar cambios en Rosario. Publicado en el periódico: El Ciudadano. http://www.elciudadanoweb.com/?p=382652

DEL FRADE, Carlos (2014). Ciudad Blanca Crónica Negra. Editorial: Último Recurso. Rosario, Argentina.

FORBES MÉXICO (2014). Las 50 ciudades más violentas del mundo. http://www.forbes.com.mx/las50-ciudades-mas-violentas-del-mundo/

GIARRACCA, Norma (2008). La Argentina y la democratización de la tierra. Publicado en Laboratorio Cambio Estructural y Desigualdad Social (CEyDS) / Facultad de Ciencias Sociales, UBA. http://www.lavboratorio.sociales.uba.ar/textos/lavbo22.pdf 
GONZÁLEZ CASANOVA, Pablo (2009). De la sociología del poder a la sociología de la explotación: pensar América Latina en el siglo XXI / Pablo González Casanova; compilador Marcos Roitman Rosenmann- Bogotá: Siglo del Hombre Editores y Clacso.

GORELIK, Adrian (2006). Cultura urbana latinoamericana: un canon y sus destiempos. Brújula; Lugar: Davis, California; Año: 2006 vol. 5 p. 9 - 44. Sitio Web http://www.conicet.gov.ar/new_scp/detalle.php?keywords=\&id=21866\&articulos=y

HARVEY, David (2007) 1973. Urbanismo y desigualdad social. ED. Siglo XXI.

LAGARRIGUE, Patricia (2013). En Rosario hay 70 mil viviendas deshabitadas y problemas para alquilar. Publicado en el periódico: La Capital. http://www.lacapital.com.ar/la-ciudad/En-Rosariohay-70-mil-viviendas-deshabitadas-y-problemas-para-alquilar-20130412-0053.html

LIFSCHITZ, Miguel (2008). Exposición primero de agosto, Bolsa de Comercio Rosario. http://www.bcr.com.ar/Pages/Publicaciones/inforevista.aspx?ldArticulo=59,

(2010). Lifschitz llamó a encontrar soluciones para el déficit de viviendas. Publicada en la página oficial del Municipio Rosario. http://www.rosario.gov.ar/sitio/noticias/buscar.do?accion=verNoticia\&id=14219

QUIJANO, Aníbal (2000). Colonialidad del poder, eurocentrismo y América Latina. Publicado en biblioteca virtual de Ciencias Sociales de América Latina y el Caribe, de la red de centros miembros de CLACSO. http://www.clacso.org.ar/biblioteca

PRADILLA, Emilio (2008). Desindustrialización, tercerización y estructura metropolitana: un debate conceptual necesario. Publicado en Cuadernos del CENDES.

PEREA, Carlos Mario, et al. (2014). La paradoja latinoamericana: las ciudades en perspectiva comparada. Publicado en Ciudades en la encrucijada: Violencia y poder criminal en Río de Janeiro, Medellín, Bogotá y Ciudad Juárez. Diseño e impresión Pregón S.A.S. Colombia, Medellín.

REBORATTI, Carlos (2010). Un mar de soja: la nueva agricultura en Argentina y sus consecuencias. Publicado en Revista de geografía Norte Grande. Versión On-line ISSN 0718-3402

RIGOTTI, Ana María; Martínez de San Vicente, Isabel (1991). Rosario: progreso y esplendor del siglo XX, Rosario, Ediciones de aquí a la vuelta, Fascículo 11.

ROULET, Néstor (2013). Falta de dólares. Publicado en agrositio.com http://www.agrositio.com/vertext/vertext.asp?id=143914\&se=14

SEOANE, José (2013). El territorio es un espacio central en la disputa sociopolítica. Publicado en enredando.org.ar. http://www.enredando.org.ar/2013/06/27/el-territorio-es-un-espacio-centralen-la-disputa-sociopolitica/

SCHVARZER, Jorge (1996). La industria que supimos conseguir. Planeta, Buenos Aires, Argentina.

SIERRA, Gustavo (2014). Sinaloa - Medellín - Rosario. Editorial: Planeta. Buenos Aires, Argentina. 
SVAMPA, Maristella (2006). Las fronteras del gobierno de Kirchner. Publicado en Pañuelos en Rebeldía. http://www.panuelosenrebeldia.com.ar/content/view/590/216/

TOPALOV, Christian (2001). La urbanización capitalista, algunos elementos para su análisis. EDICOL México.

VAINER, Carlos Bernardo (2000). Pátria, empresa y mercadoria. Publicado em Notas sobre a estratégia discursiva do Planejamento Estratégico Urbano. Arantes, O, C. Vainer y E. Maricato (eds.), A cidade do pensamento único. Desmanchando consensos. Petrópolis: Editora Vozes. y/o Video de Entrevista GPU (Grandes Proyectos Urbanos) Brasil.

WALLERSTEIN, Inmanuel (1988). The modern world-system. Adobe PDF E-Book ISBN: 9780520948570

\section{Entrevistas}

Bielsa María Eugenia, realizada el día miércoles 12 de junio de 2013. (Arquitecta, exVicegobernadora de Santa fe, ex-Concejal de Rosario de Frente para la Victoria, renunció a su cargo de diputada provincial ganado en 2011 por diferencias con Agustín Rossio. Profesora de Urbanismo en la UNR).

Cortés Alberto, realizada el día martes 11 de junio de 2013. (Concejal de Proyecto Sur, Concejal 2001-2005 del Partido Socialista Auténtico. Docente e investigador de la UNR).

Trabalho enviado em 02 de setembro de 2015.

Aceito em 18 de outubro de 2015. 